\title{
Effect of vibration after filling on mechanical reliability in thin wall investment casting with fillability filling regime-part 1
}

\author{
Waleed Abdul-Karem • N. Green • Khalid F. Al-Raheem • \\ Abbas H. A. Hasan \\ Received: 25 December 2011 / Accepted: 5 November 2012 /Published online: 15 January 2013 \\ (C) The Author(s) 2013. This article is published with open access at Springerlink.com
}

\begin{abstract}
A vibration technique is used in this study to explore the effect of low frequency vibration on the mechanical reliability of Al-7Si-Mg castings. The quality of castings is related to the number and the size of porosity and oxide film in thin wall investment casting. The quality of each method of casting (casting with and without vibration) was assessed by the density of the defects within the thin strips. Weibull distribution function is used to analyze the tensile strength data. The Weibull modulus is applied as a criterion to assess the mechanical reliability to identify the optimized casting condition. The results show that the effect of the vibration on the mechanical reliability is markedly dependent on acceleration of vibration, and the Weibull modulus is in the range of 12 to 12.7 when the acceleration is in range of 0 to $1 \mathrm{~g}$; however, in more than $1 \mathrm{~g}$, the range is $30-35$.
\end{abstract}

Keywords Vibration · Thin wall investment casting · Mechanical reliability

W. Abdul-Karem • A. H. A. Hasan

Department of Mechanical and Industrial Engineering, Caledonian College of Engineering, P.O. Box 2322, COP Seeb PC 111, Oman

W. Abdul-Karem

e-mail: waleed@caledonian.edu.om

W. Abdul-Karem

University of Birmingham, Birmingham, UK

N. Green

Mechanical Engineering, University of Birmingham,

Birmingham, UK

K. F. Al-Raheem ( $\triangle)$

Mechanical and Mechatronics, Sohar University, P.O. Box 44,

Sohar PC 311 Muscat, Oman

e-mail: KAbdulraheem@soharuni.edu.om

\section{Introduction}

Filling defects in thin will investment casting can be caused by many different foundry parameters, such as high gas content, an unsound filling system design, or insufficient feeding. These defects are presented in casting as a feature of the bubble, oxide film, and porosity [1-3].

Bubbles, formed as a result of the folding of the free surface, are entrained in the bulk of the liquid metal. Oxide entrainment is known to lead to nucleation of other casting defects, such as gas pores, intermetallic phases, and shrinkage pores; the oxide acting to heterogeneously nucleate these defects [4].

As a result of the instability in the free surface of the liquid metal bubbles and oxide entering the bulk of the metal and then being randomly distributed under the effect of bulk turbulence, eventually, oxide films are frozen inside the casting and become the sources of the cracks or hot tears which damage the casting $[5,6]$. The number, size, and distribution of the entrained defects are strong determinants of the scatter of the mechanical properties of castings.

Weibull distribution is a good statistical method to describe the distribution of the mechanical properties of castings and the Weibull modulus of tensile strength has been used to quantify reliability as a function of filling $[7,8]$. The Weibull modulus indicates the scatter of the mechanical properties of castings, the lower the value of the Weibull modulus, the greater the scatter of the mechanical properties, and this reflects unreliable casting performance.

Over the years, the Weibull distribution has been a powerful tool to describe the mechanical property data of material which failed because of a single defect and has been established in engineering materials as a tool in the field of fracture, due to its mathematical simplicity and relatively high success in describing most data [9].

The first introduction of the Weibull statistic to quantify the randomness of the properties and the effect of surface 
Fig. 1 a, b Ceramic moulds design to produce test pieces with thickness of $0.75 \mathrm{~mm}$ for a tensile test
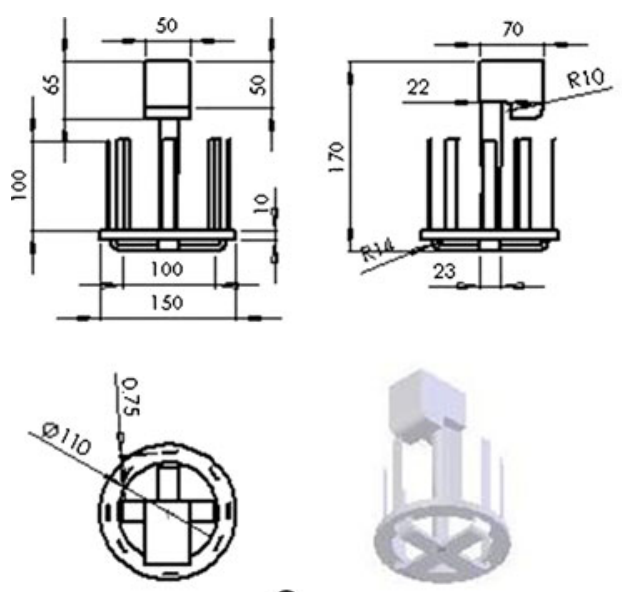

a

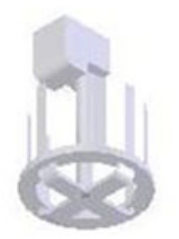

turbulence has been applied by Green [10]. It was found that where the surface turbulence results from the metal velocity in the range of $40-80 \mathrm{~m} / \mathrm{s}$, the Weibull modulus is in the range of 1 to 5 ; however, in good gravity filling system, the range is $50-150$. Campbell and Green have studied the effect of surface turbulence on mechanical reliability of Al-7Si-Mg castings $[11,12]$.

During the investigation of filling defects such as porosity and oxide films and their effect on the quality of casting for Al-7Si-Mg alloy, Green and Campbell [13] found that filling defects were associated with a scatter of tensile properties and Weibull modulus; this reflected on the reliability of the casting. Nyahumwa and Green [14] used the Weibull modulus to indicate the quality of casting during their investigation of the oxide film effect on the fatigue life properties.

It is therefore the objective of the work reported to assess in a comprehensive manner the effect of vibration after filling on the mechanical reliability of thin wall investment castings under the control of fillabillity only. Investment casting methods at temperature above the liquidus have been filled with A356 alloy.

\section{Experimental and result}

The experiments were induced to assess the influences of vibration on the tensile reliability of thin wall investment

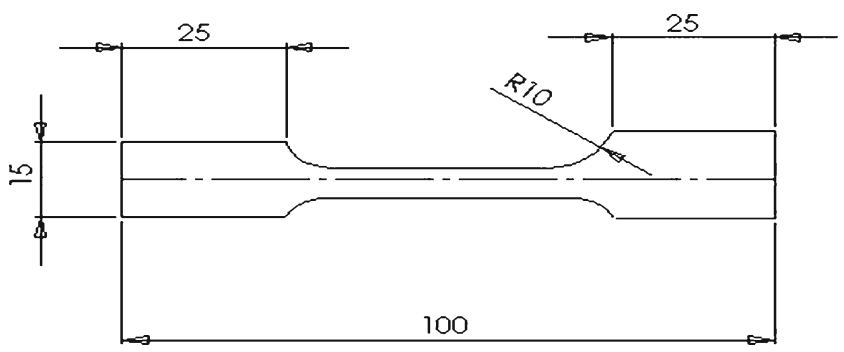

Fig. 2 Specimen geometry castings conducted. A Weibull modulus for the tensile strength and elongation of strip specimens with thickness of $0.75 \mathrm{~mm}$, cast with and without vibration, is used as the indicator of reliability of the castings.

A bottom-filled system is designed with test pieces oriented vertically and cast into ceramic moulds. The design is illustrated in Fig. 1. The running system is designed in accordance with the rules set out by Campbell [15] such that at the ingates, the metal velocity would not exceed the critical velocity of $0.5 \mathrm{~m} / \mathrm{s}$.

Four groups of castings are made without vibration, with vibration of 0.8 and $1.2 \mathrm{~g}$ acceleration after filling and casting with $0.8 \mathrm{~g}$ acceleration of vibration during filling. Three moulds are cast for each vibration condition, each mould consisting of a ten test pieces. All castings are poured at a temperature of $750-755^{\circ} \mathrm{C}$.

\subsection{Casting without vibration}

The moulds cast without vibration are poured under fillability filling type conditions (mould temperature $660-700{ }^{\circ} \mathrm{C}$ ) with a metal head of $120 \mathrm{~mm}$ above the top of the test strips which is sufficient to "force" the melt into the test pieces.

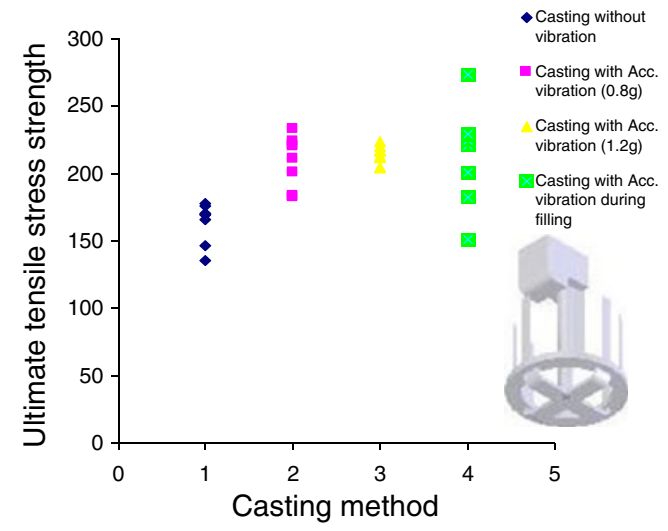

Fig. 3 Scatter plot of the ultimate tensile strength of the test pieces for each group of castings' fillability filling condition 


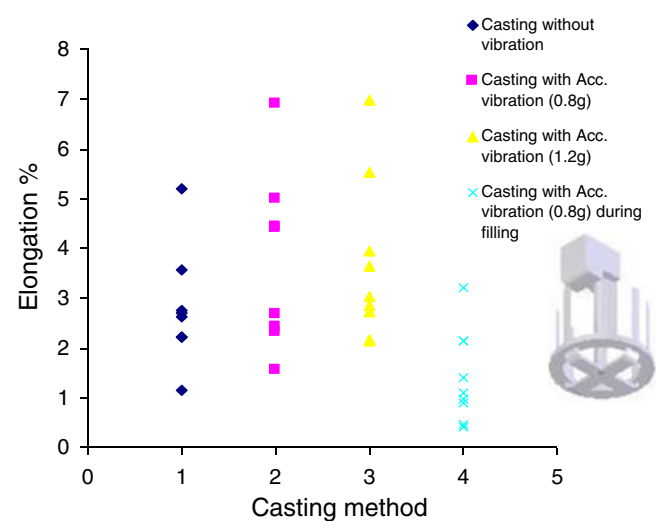

Fig. 4 Scatter plot of the elongation percent to failure of the test pieces for each group of castings

\subsection{Casting with vibration (less than $1 \mathrm{~g}$ )}

The second group is casted with a $0.8-g$ acceleration of vibration applied immediately after the filling process with a metal head of $65 \mathrm{~mm}$ which is enough to fill the test pieces.

\subsection{Casting with vibration (more than $1 \mathrm{~g}$ )}

The third group is casted with $1.2 \mathrm{~g}$ acceleration of vibration applied after the filling process in fillability filling type conditions with metal head of $50 \mathrm{~mm}$. The fourth group is casted with $0.8 \mathrm{~g}$ acceleration of vibration applied during filling process in the fillability filling type condition with metal head of $65 \mathrm{~mm}$.

The test pieces are machined using a side-cutting mill to produce tensile test specimens conforming to British standard [16]. The geometry of the specimens is shown in Fig. 2.

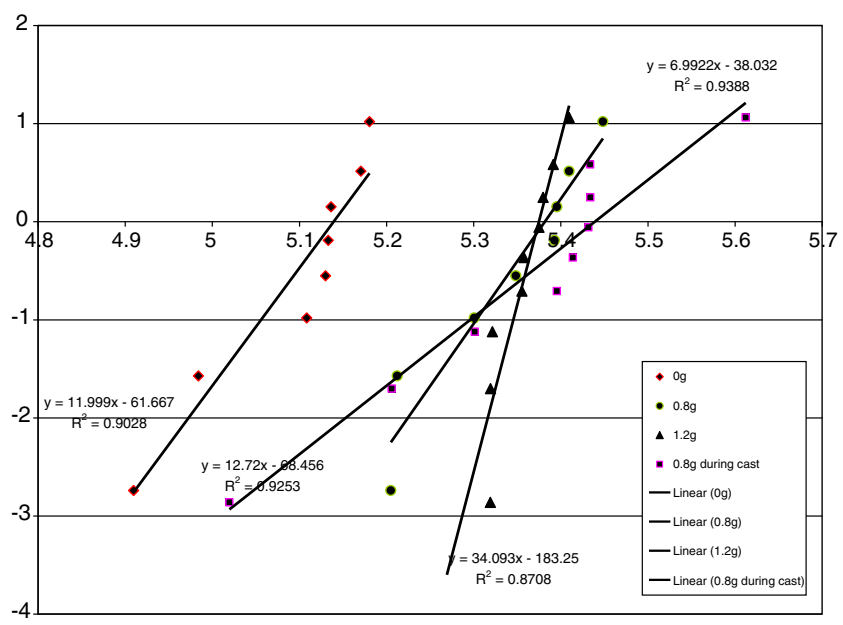

Fig. 5 Weibull plots of UTS data for each method of casting

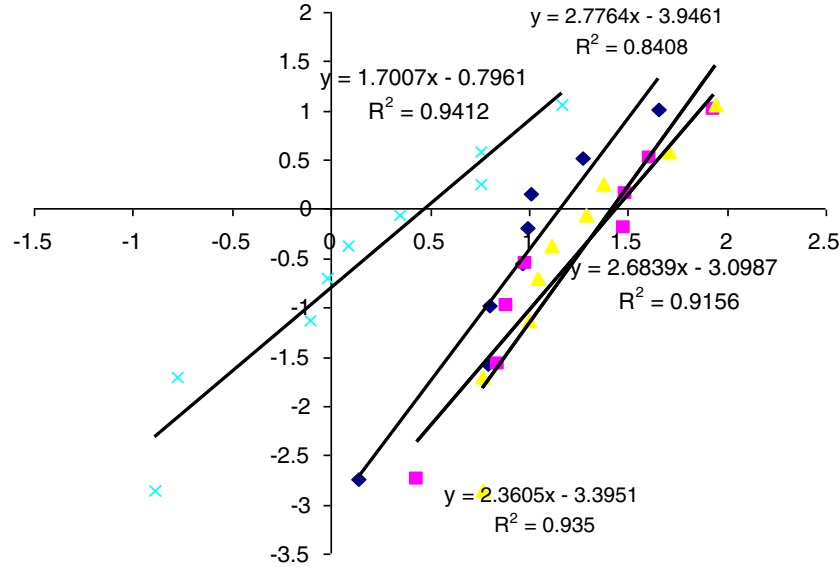

Fig. 6 Weibull plots of elongation data for each method of casting

Test pieces are heat treated to near peak-aged condition: solution treated for $6 \mathrm{~h}$ at $540 \pm 5{ }^{\circ} \mathrm{C}$, quenched in water at room temperature, then artificially aged at $160 \pm 5^{\circ} \mathrm{C}$ for $4 \mathrm{~h}$. Tensile testing is carried out using a computer-controlled $200 \mathrm{kN}$ dynamic loads servo-hydraulic testing machine (Zwick).

The ultimate tensile strength and the elongation to failure of the ten test pieces for each method of casting are plotted in Figs. 3 and 4. Generally, the figures indicate that the ultimate tensile strength and elongation progressively increase from casting without vibration to casting with vibration.

A Weibull distribution function is used to qualify the scatter in ultimate tensile strengths (UTS) obtained from each casting method. A Weibull plot of all UTS is shown in Fig. 5 and elongation to failure in Fig. 6.

To evaluate the vibration influence on the quality of casting, a sample calculation was done to investigate the vibration effect on the Weibull parameter value $\sigma$ (ultimate tensile stress) in each method of casting, using the data which are available in Fig. 5.

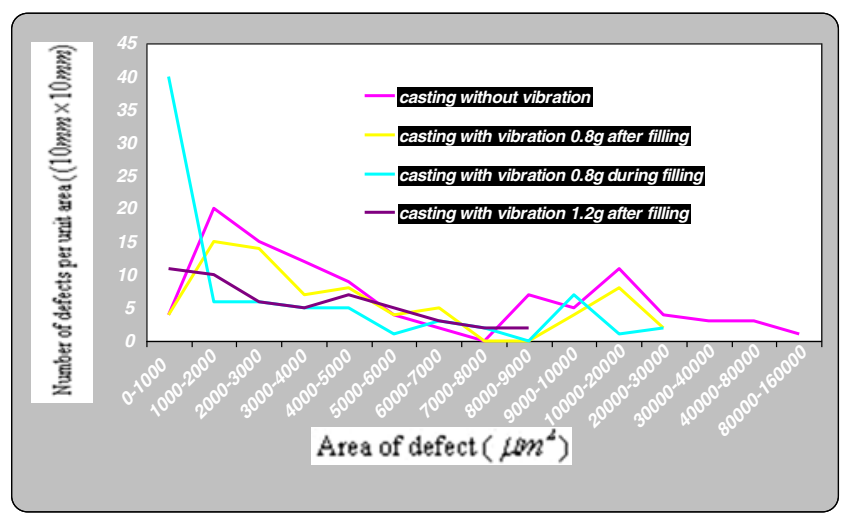

Fig. 7 The distribution of defects for each method of casting 
Fig. 8 a SEM micrographs of the frame chose randomly from each method of casting: $a 1$ casting without vibration, $a 2$ casting with vibration after filling. b EDX spectrum for each phase: $b 1$ casting without vibration, $b 2$ casting with vibration after filling

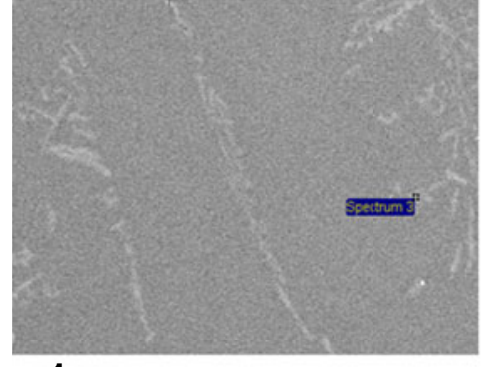

a1 casting without vibration

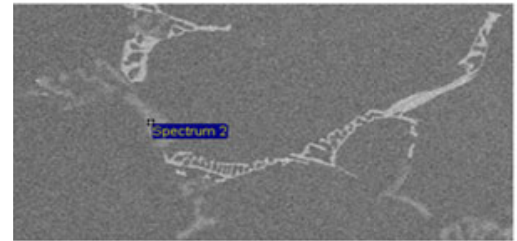

a2 casting with vibration after filling

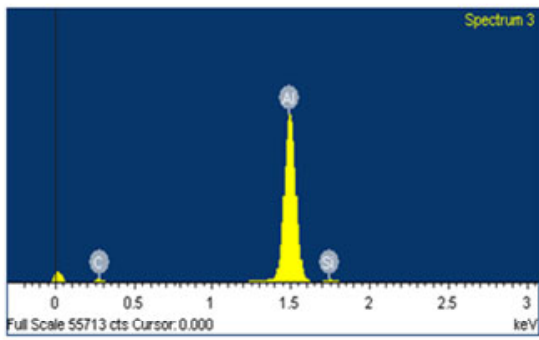

b1 casting without vibration

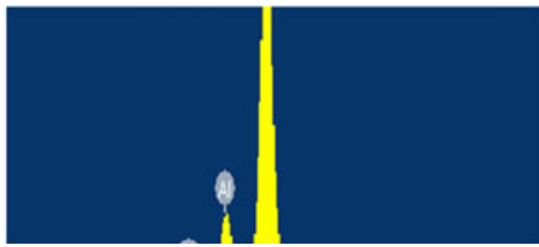

b2 casting with vibration after filling
Assessment of the position parameter indicates that the position parameter of the castings made with acceleration from vibration of $1.2 \mathrm{~g}$ was found to be $216 \mathrm{MPa}$, compared with $170 \mathrm{MPa}$ in the casting without vibration. This indicates vibration has a positive input on performance of the castings.

In order to evaluate the quality of the casting which was obtained from each method of casting, a quality correlation $Q=\mathrm{UTS}+(150 \times \log ($ elongation $))$ was used to estimate the quality for each method of casting.

In the present work, metallographic examination with minimum of 30 fields of view is used to assess the size, quantity, and distribution of casting defects formed within each group of casting. The distribution of defect sizes in each method of casting is illustrated by Fig. 7 .

Optical microscope and secondary electron micrographs (SEM) were used to examine the phase and structure in each method of casting and identify such defects as bubbles, oxide films, or any other defects (see Figs. 8 and 9).

Microfractographic examination on the surfaces of tensile test pieces from each method of casting was studied using a JEOL 6060 scanning electron microscope. Digital images were captured and illustrated in Fig. 10

Finally, the best fit parameters in Fig. 5 and quality $Q$ with respect to the number of defects $N$ are summarized in Table 1, together with the correlation coefficient $R$.

\section{Discussion}

In casting, the stability of the free surface to prevent the entrainment of the surface film as the result of the folding action on the free surface from entering the bulk of the liquid metal and then damaging the casting is considered [17]. The Weber number (a dimensionless number, inertial with the surface tension pressure, which can be evaluated by the correlation $\left.\mathrm{We}=v^{2} \rho \mathrm{r} / \gamma\right)$ characterizes the relative free surface stability of a fluid flow. When $\mathrm{We}=1$, the free surface becomes unstable and surface turbulence can arise.

In the present work, the Weber number was found to be 0.013 when the velocity due to acceleration was $0.12 \mathrm{~ms}^{-1}$
Fig. 9 Polished surface with an area of $10 \mathrm{~mm} \times 10 \mathrm{~mm}$ from the casting a with vibration and b without vibration showing the microstructure and the defects as collapsed bubble, gas pores, and shrinkage pores

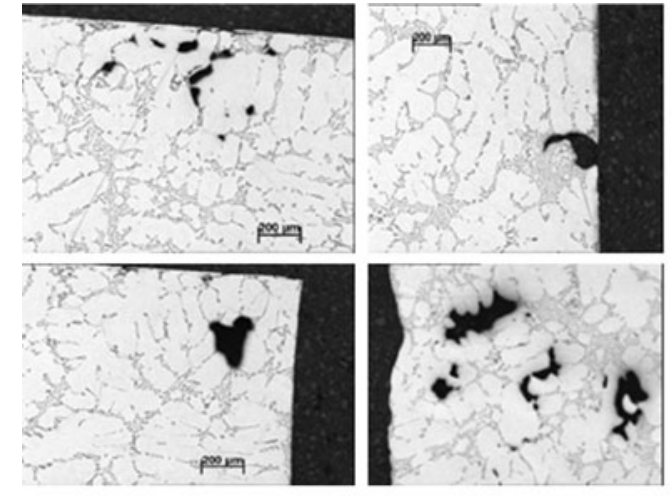

a

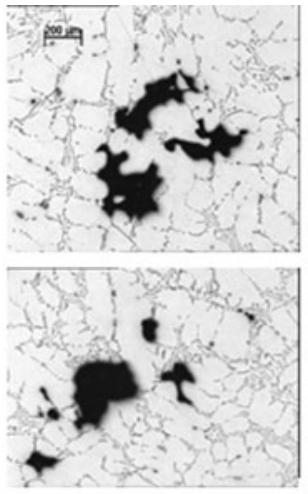

b

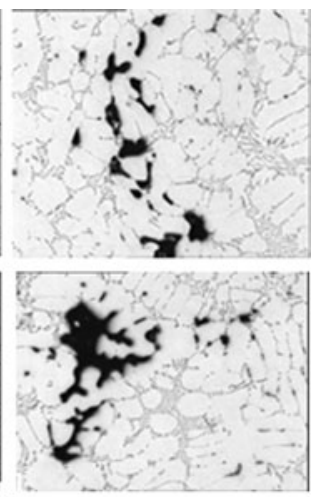


Fig. 10 SEM of fracture surface of each group of casting with high tensile strength containing gas porosity on the edge of the casting, showing oxide film covering the dendrites
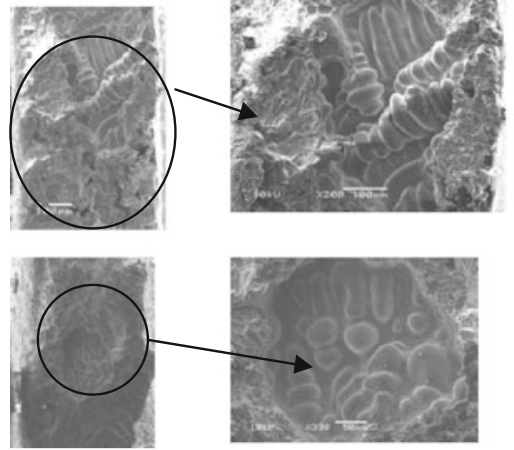

Casting without vibration
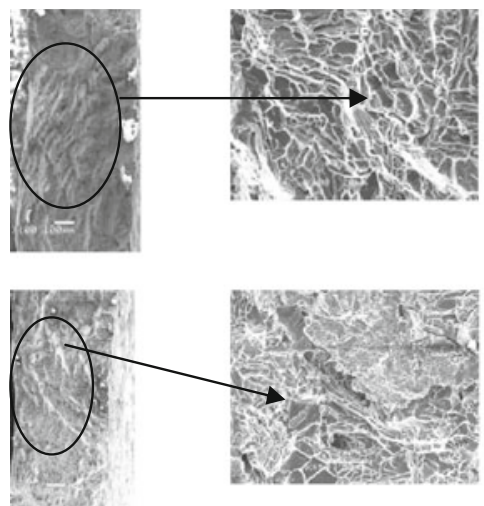

Casting with $1.2 \mathrm{~g}$ acceleration vibration after filling

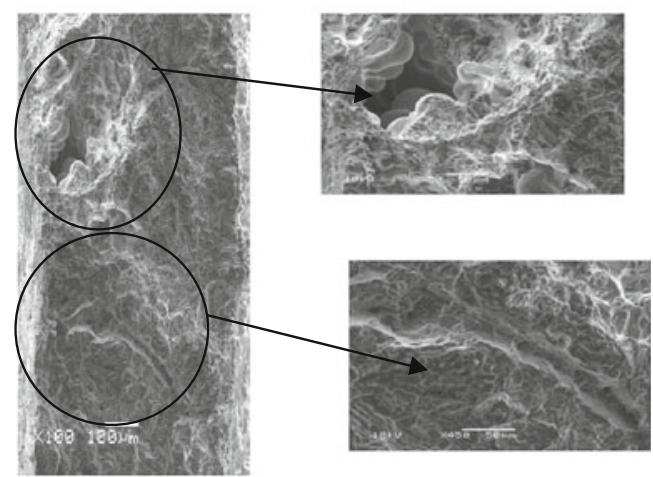

Castin gwith $0.8 \mathrm{~g}$ acceleration vibration after filling
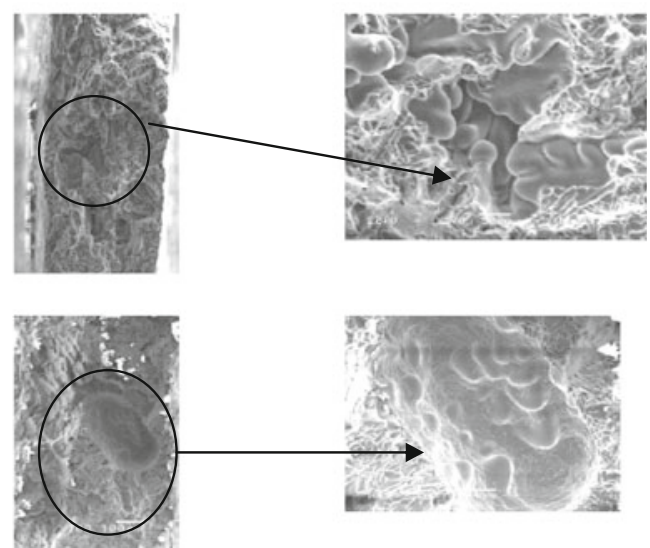

Casting with $0.8 \mathrm{~g}$ acceleration vibration during filling
$\left(U_{\max }=2 \pi f a\right)$. This indicates that the surface tension is a control parameter effect on the stability of the free surface in the fluid flow. Therefore, it is expected that less folding action on the free surface and entrainment can occur when the liquid metal flows in a thin section with dimensions less than $0.75 \mathrm{~mm}$. So, it is considered that most of the surface film entrainment in thin wall investment castings with and without vibration was generated in a feature of the runner system, such as a basin or sprue. Such a view can be shown in Fig. 11.

In general, defects such as gas porosity were found in the polished casting for all groups of castings as shown in Fig. 9. Examination also identified surface depression and collapsed bubbles on the surface. No oxide films were observed in the middle of the castings, but a number were found at the edge. Generally, the large oval pores accumulated in the middle of the casting, but were small in size, of the gas pores accumulated in the edge, gas pores usually associated with the Al-Si eutectic phase, or grain boundaries. Figure 10 shows that the fracture surface exhibitis localized failure of the aluminum matrix and also contains bubbles and pores as casting defects, and by using EDX analysis, we identified another defect as wrinkled oxide film; it was observed around the dendrite. Sometimes the draped oxide film peels off the dendrite and is shown in Fig. 10.

Figure 8 shows that the microstructure for all the casting alloys was similar and every method of casting shows phase and structure typical of A356 alloys [18]. This indicates that the vibration action in the casting had no effect on the microstructure when casting in the fillability filling type condition and confirms that the improvement in quality is dependent on the size and number of casting defects.
Table 1 The best fit parameters of the Weibull plots and quality index, number of defects, and $R^{2}$ for Weibull best fit data

\begin{tabular}{llllll}
\hline Method of casting & $Q$ & $\lambda$ & $\sigma$ & $N$ & $R$ \\
\hline Casting without vibration & 230 & 12 & 170 & 97 & 0.9028 \\
Casting with vibration (0.8) (after filling) & 295 & 12.7 & 187 & 61 & 0.9253 \\
Casting with vibration (1.2g) (after filling) & 295 & 34 & 216 & 51 & 0.8708 \\
Casting with vibration (0.8) (during filling) & 229 & 7 & 225 & 71 & 0.9388 \\
\hline
\end{tabular}



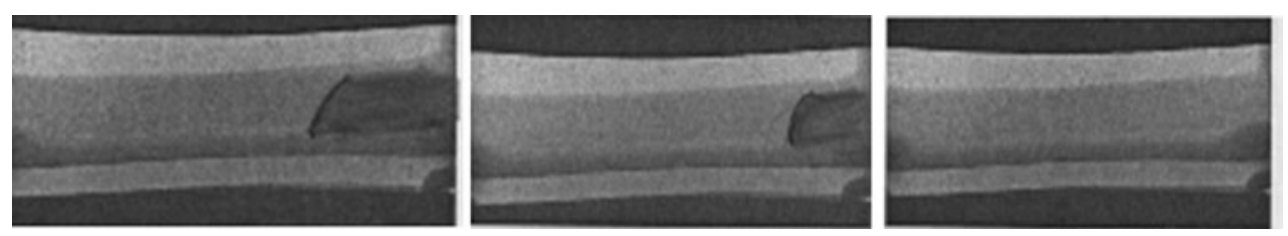

Fig. 11 Images from 1 to 5 show that the liquid metals flow in thin section under surface tension control, real time X-ray, test piece thickness of $0.75 \mathrm{~mm}$, mould temperature $400{ }^{\circ} \mathrm{C}$, by pouring

Cumulative probability distributions of defect size were plotted for each method of casting and they are illustrated in Fig. 12. The data in this figure show that the maximum defect size was reduced when the acceleration of vibration increased. This indicates that distribution of casting defect sizes is affected by mould vibration. Thereby, it is necessary to qualify the filling sequence in each method of casting. In the present work, the surface film entrainments were formed in the basin, due to pouring of the charge from the crucible into the basin and within the running system.

\subsection{Casting without vibration}

In the case of casting without vibration, the entrained oxides moved within the metal stream sections which appeared to hold back the flow and delay entry of the liquid metal into the section; this situation caused the surface film entrainment to be arrested at the entrance of the thin section or to float to the surface of the upriser, in the case of bubbles (see Fig. 13 (1-6)). During this period, the main liquid metal continued to flow into the upriser and build a metal head greater than the critical metal head. Liquid metals would again start to flow into the thin section under the control of surface tension, while the oxides that are smaller than the width of the section enter it as part of the stream, but no surface folding action was observed during this stage.

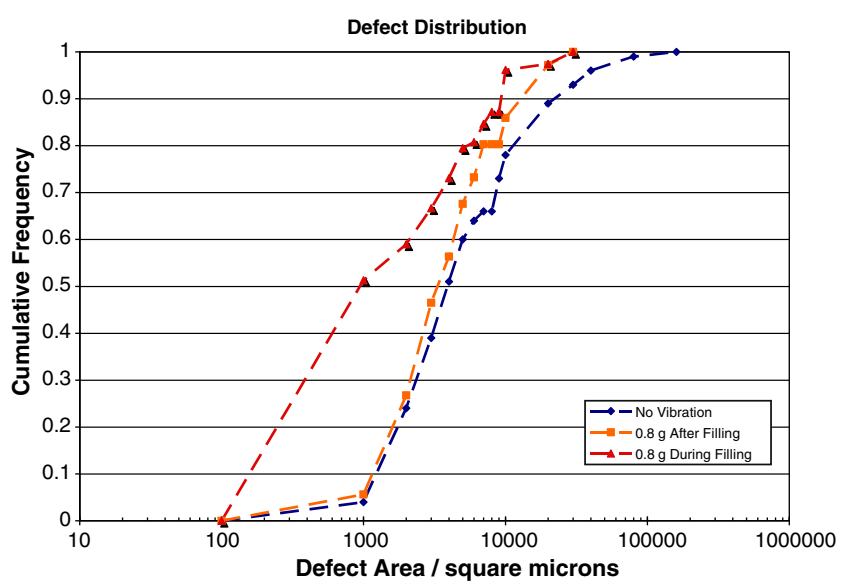

Fig. 12 Cumulative probability distributions of defect size in each method of casting

\subsection{Casting with vibration}

When the vibration is applied after filling, vibration pressurized the liquid metal into the thin section, as described above. During the arresting phase, the entrained surface films precipitated in the gate of the runner system under the action of gravity, such as oxide film or floated to the surface such as porosity. As the metal then starts to flow discontinuously into the thin section, most of the small bubbles move from the bulk of the liquid to the interfacial surface between the mould and the liquid metal, due to the momentum force which is generated from vibration, thereby causing the small bubbles to adhere to the wall surface. Bubbles creep on the surface in the direction, as a result of the vibration movement, until it reaches the free surface of the liquid front and bursts (see Fig. 9a). However, oxide film was observed close to the edges surface of the strips in the vibrated castings. It may be that the old and young oxide film [5] moves to the surface of the casting as a result of the nature of the flow propagation (discontinuous flow) under vibration conditions [18] (see Fig. 14).

When vibration was applied during the filling process, practically, in the part of the basin and sprue, the surface film entrainment as a result of the turbulence motion generated on the surface by vibration influencing the equilibrium hydrodynamic system; but this energy in the present work is not enough to create droplet ejection phenomena. The entrained surface film moved with the metal stream as the liquid flowed in the basin, sprue, and gate in the runner system and into the thin sections without delay. However, only entrained surface oxide films smaller in size than the channel thickness can pass. After the liquid metal entered the thin section and started to flow within it, the free surface of the liquid front became stable because the fluid flow was controlled by the surface tension at this stage. This indicates that more surface film entrainment can occur in casting using vibration during filling than in casting using vibration after filling.

The Weibull analysis of the tensile strength data of the samples subjected to vibration indicates that there is a clear advantage for the thin wall investment casting to have an acceleration of vibration of $1.2 \mathrm{~g}$ after filling, since the reliability, as quantified by the Weibull Modulus, is trebled. However, there is only a small improvement to the reliability 


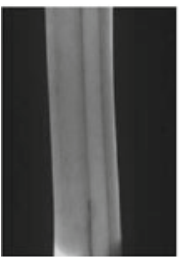

(1)

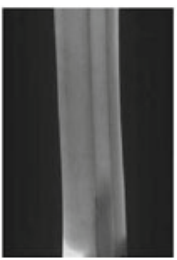

(2)

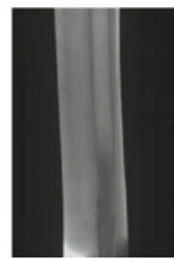

(3)

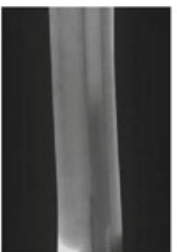

(4)

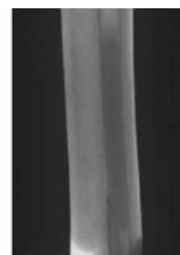

(5)

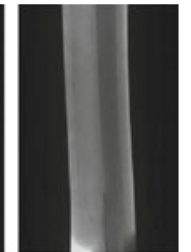

(6)

Fig. 13 Frames from real-time X-ray video showing the strip with thickness of $0.75 \mathrm{~mm}$, set in vertical direction, cast without vibration, A356 alloys, using fillability filling type, mould temperature of $660-700{ }^{\circ} \mathrm{C}$, and pouring temperature of $750{ }^{\circ} \mathrm{C}$

of the casting with an acceleration of vibration of $0.8 \mathrm{~g}$ after the filling process.

Table 1 shows that the quality of the casting with vibration after filling in a fillability filling type test is more reliable than casting without vibration, in proportion to the number of the oxides, gas pores, bubbles, and shrinkage pores in the castings.

In the case of casting without vibration, the Weibull modulus was 12 . When applying $0.8 \mathrm{~g}$ acceleration of vibration after filling, the Weibull modulus became 12.7. This indicates that the small improvement in reliability is governed by the driving force of the flow of the liquid metal, generated from the vibration application. This force seems to reduce the number and size of the defects, such as gas pores and shrinkage pores, in the casting. This is reflected in the distribution of these defects, thereby reducing the scatter in strength. Surprisingly, in casting with an acceleration of vibration $1.2 \mathrm{~g}$, the modulus is trebled from 12 to 32 . This improvement in reliability is highly significant and is believed to come from the increase of the force of the acceleration due to vibration, which breaks and removes most of the small gas pores and oxide film in the casting (see Figs. 9 and 14). Some of these small pores escape to the free surface of the liquid by floating and bursting, and others are removed by the driving force generated due to acceleration from the bulk of the liquid to the interfacial surface between the metal and the mould. The nature of the propagation flow of the liquid metal during vibration assists these pores to creep to the surface of the mould until they reach the free surface of the liquid, where they burst.

However, the reliability was reduced when vibration with $0.8 \mathrm{~g}$ acceleration is used during filling. This may result when the metal flow in the casting feature (basin, sprue, and gate) is turbulence flow resulting from vibration and is generated on the free surface of the liquid. This increases the folding action on the surface, thereby increasing the surface film entrainment in the bulk of the liquid. Moreover, there is no delay between filling of the side risers and strips nor accumulated surface film in the gate of the runner system. This assists much of the surface film entrainment to pass into the thin section when the liquid metal flows inside the thin section.

The result of the Weibull analysis of the elongation reveals no great improvement in reliability between the castings made without and with vibration $(1.2$ and $0.8 \mathrm{~g}$ ) after filling. Low reliability was found with casting with vibration of $0.8 \mathrm{~g}$ acceleration during filling (see Fig. 6). This indicates that vibration during the casting phase increases the distribution of the elongation properties. This is perhaps caused by the small number and size of the gas pores and shrinkage pores with a specimen cast with $1.2 \mathrm{~g}$ vibration after filling. However, vibrations decrease the distribution of elongation in the casting when vibration is applied during filling. This could be caused by a large number of defects such as pores in the casting.

\section{Conclusion}

Entrained surface oxide films in the thin wall investment castings appear as gas pores associated with oxide films and shrinkage porosity. All were responsible for failure of tensile specimens and scatter of the mechanical properties.

Quantity and distribution of casting defects are affected by filling sequence in each method of casting. Surface tension is a control parameter effect on the stability of the free surface in the fluid flow, thereby no entrainment (pores and oxide surface film) will be generated in thin wall investment casting in both casting methods.

The Weibull modulus of the UTS of batches of specimens cast with and without vibration showed that for all accelerations $<1 \mathrm{~g}$, the material was inherently unreliable with a Weibull modulus of tensile strength in the range 12 to 12.7 . Sample cast with an acceleration of $1.2 \mathrm{~g}$ shows
Fig. 14 SEM show the oxide film extruded to the edge of the test piece 0.75 -mm-thick casting with $1.2 \mathrm{~g}$ acceleration of vibration
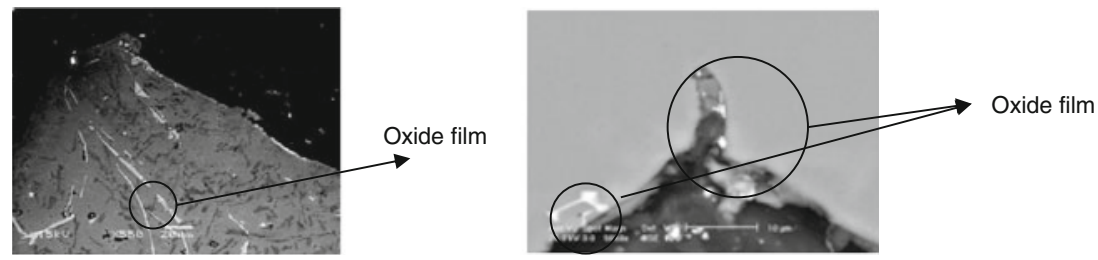
significantly improved reliability with a Weibull modulus of UTS of 38. Improvement in reliability of mechanical is governed by the driving force of the flow of the liquid metals, generated from the vibration application.

Open Access This article is distributed under the terms of the Creative Commons Attribution License which permits any use, distribution, and reproduction in any medium, provided the original author(s) and the source are credited.

\section{References}

1. Green N, Campbell J (1994) Influence of oxide film filling defect on the strength of Al-7\% Si-Mg alloys casting. Trans AFS 102:341-347

2. Campbell J (2004) Properties of cast metals, 66th World Foundry Congress, 6-9 September, Istanbul, Turkey

3. Campbell J (2003) Casting defect in vacuum-investment-cast Nibase turbine blade. Trans Metall

4. Campbell J (1988) Thin wall casting. Mater Sci Technol 4:194-204

5. Flemings MC (1974) Solidification process. McGraw-Hill, New York, pp 219-229

6. Campbell J (1995) Review of fluidity concepts in casting. Cast Metals 4:227-237
7. Iida T, Guthrie RIL (1988) The physical properties of liquid metals. Oxford University Press, Cambridge

8. Keene BJ (1993) Review of data for the surface tension of pure metals. Int Mater Rev 38:157-192

9. Khalili, Kromp K (1991) Statistical properties of Weibull estimation. J Mater Sci 26:6741-6452

10. Campbell, Li DZ (2004) Filling system for investment casting Nibase turbine blade. J Mater Process Technol 148:310-316

11. Green N, Campbell J (1993) Statistical distributions of fracture strength of casting A17\%Si-Mg alloy. Mater Sci Eng A 173:261266

12. Wachter WJ (1955) Written discussion on "influence of vibration on fluidity and filling investment casting on aluminium". AFS Trans 63:686

13. Cabeza, Gibiat V, Negreira C (2003) Observation of height localized structures in Faraday experiment with height dissipative fluids. Physica A 327:34-38

14. Campbell J (2004) Casting practice the 10 rules. Butterworth Heinemann, Oxford

15. British standard (2000) BSEN 10002: part 1

16. Campbell J (2003) Casting, 2nd edn. Elsevier, Oxford

17. Backerud L, Chai G, Tamminen J (1990) Solidification characteristic of aluminum alloys: foundry alloys, vol 2. American Foundry Society, Schaumburg

18. Karem WA, Green N, Al-Raheem KF (2012) Vibration assisted filling capability in thin wall investment casting. Int J Eng Sci Technol 61(9-12):873-877 